\title{
Estudio iconográfico de las imágenes femeninas de la cerámica predinástica de Nagada II
}

Elena DE GREGORIO

Este artículo presenta un estudio acerca de las representaciones femeninas que aparecen dibujadas en algunos vasos del período predinástico de Nagada II. Dicha iconografía, de marcado carácter simbólico, nos permite sugerir diversas hipótesis que podrían explicar las distintas actitudes que las imágenes femeninas adoptan en los esquemas figurativos en los que están representadas, así como sus posibles significados.

\section{Iconographic study of the female images on the Naqada II pottery vessels}

The paper outlines a study of the female images represented on some of the high quality vessels of the Naqada II period. The iconography contains marked symbolism which will be considered. Several hypotheses will be suggested to explain the distinct and differing attitudes adopted by the female figures in the figurative compositions.

KEY WORDS: Naqada II, pottery, female representations

$\mathrm{E}_{\mathrm{e}}^{\mathrm{n}}$ el conjunto de vasos que fueron modelados en el periodo de Nagada II (ca. 3600-3200 a.C.) existe un cierto número de ejemplares de gran calidad, realizados con arcillas margosas ${ }^{1}$ que presenta decoraciones pintadas en rojo sobre superficies claras en tono rosáceo, blanquecino o verdoso ${ }^{2}$. Entre los diferentes diseños que muestran estas piezas se encuentran las figuras femeninas que van a ser objeto de estudio en el presente artículo.

La mayoría de los vasos cerámicos a los que vamos a hacer referencia han sido elegidos porque de ellos conocemos todas las imágenes que componen las escenas representadas así como su lugar de procedencia. Como indican Wengrow y Baines $^{3}$, a pesar del hallazgo de fragmentos de estas cerámicas decoradas en zonas de hábitat, su presencia en dichos lugares es reducida; por ello, vamos a considerar aquí que el contexto de uso de estas piezas es el funerario, es decir, que son recipientes creados para acompañar al difunto.

Las representaciones humanas que aparecen en estos vasos, a pesar de su esquematismo, permiten distinguir entre mujeres y hombres. En la mayoría de los casos, las figuras femeninas presentan el torso como un triángulo invertido relleno de color que apoya sobre otra forma geométrica similar, más alargada, que sugiere las piernas (figs. 2, 3b, 4 y 6), aunque existen ejemplos en que dichas imágenes parecen llevar una especie de falda o de vestido más corto que permite ver los pies (figs. 1, 3a y 5).

1. Este tipo de arcillas se obtienen de las capas margosas situadas entre los estratos de caliza del desierto arábico y líbico, cuyas pastas resultantes suelen ser densas y duras y requieren de recursos técnicos más depurados que las arcillas aluviales.

2. Tonalidades adquiridas por las arcillas margosas tras el proceso de cocción.

3. Wengrow y Baines, 2004: 1083.

Fecha de recepción: 28 de mayo de 2007

Fecha de admisión: 25 de junio de 2007

http://doi.org/10.25145/j.TdE.2009.05.01.21 
Los personajes masculinos (figs. 4, 5 y 6) muestran sus extremidades superiores e inferiores bien definidas, aparecen representados de perfil $1^{4}$, con las piernas separadas y llevan un estuche fálico. Sus cabezas suelen resultar pequeñas en relación con la dimensión de sus cuerpos, a menudo alargados.

Entre los vasos estudiados se distinguen tres posturas, más o menos frecuentes, para las figuras femeninas: las que presentan los brazos por encima de la cabeza, las que apoyan sus manos en la cadera y las que se encuentran cogidas de la mano de otra mujer o de un hombre.

\section{Mujeres que alzan los brazos por encima DE LA CABEZA}

La más común de las tres posiciones es aquella en la que se encuentran elevando los brazos por encima de la cabeza (figs. 1, 2, 3a, 4 y 5); en algunas ocasiones se dibujan las manos y entre tres y cinco dedos de las mismas (figs. 4 y 5). Dicho gesto se ha constatado también en algunos individuos representados en las cerámicas del periodo de Nagada I y en imágenes del arte rupestre en el desierto 5 .

En una pieza amratiense de los Musées Royaux d'Art et d'Histoire de Bruselas ${ }^{6}$ aparecen ocho figuras en fila; dos de ellas son más altas que el resto, elevan sus brazos y llevan un tocado de elementos vegetales o plumas sobre la cabeza. Según Scharff y Baumgartel ${ }^{7}$, las dos de mayor tamaño serían hombres, porque interpretan como el vello de las piernas las pequeñas protuberancias que quedan marcadas en las extremidades inferiores, y consideraran al resto como mujeres. Cuatro de los sujetos de menor tamaño se tocan entre sí y rodean a uno de los dos de tamaño superior; dos de ellos levantan un brazo que apoyan sobre el hombro del individuo situado en el centro. En las cerámicas de Nagada II los hombres también aparecen en algunas ocasiones tocando a las mujeres que elevan sus brazos por encima de la cabeza. Los personajes menores se encuentran de perfil, con el pelo al viento, tienen indicadas las piernas y presentan un elemento que hemos interpretado como un estuche fálico. Baumgartel cree que lo que se representa es una actuación ceremonial, pero esta autora no se arriesga a indicar cuál pudiera ser la función de tal acto ${ }^{8}$.

No podemos ofrecer una explicación de por qué en el periodo de Nagada I son los varones los que presentan este gesto y en Nagada II son las mujeres, a excepción de un vaso del que se conservan dos fragmentos en el Ashmolean Museum de Oxford $^{9}$, pero podría estar denotando un cambio cultural y religioso.

En la mayoría de los casos las figuras femeninas guerzenses que muestran este gesto suelen estar acompañadas de barcos con numerosos remos, de hecho, de los vasos cerámicos estudiados tan sólo uno de ellos carece de embarcación en su esquema compositivo (fig. 1) ${ }^{10}$. Esta pieza fue hallada en Abydos y, según Joan Crowfoot Payne, su cronología sería de Nagada IId2 ${ }^{11}$.

4. Graff indica que en Nagada II la postura de perfil es exclusivamente masculina. Graff, 2004a: 80.

5. Wilkinson, 2003: lám. 18.

6. $\mathrm{N}^{\mathrm{o}}$ de inventario: E3002. Baumgartel, 1947: 64, fig. 14.

7. Baumgartel, 1947: 64-65.

8. Baumgartel, 1947: 65 .

9. $\mathrm{N}^{\mathrm{o}}$ de inventario: 1895.819; Nagada, tumba 60. Crowfoot Payne, 2000: 112, figs. 48, 916.

10. Oxford, Ashmolean Museum, E.2832; Abydos. Crowfoot Payne, 2000: 108-109, figs. 44, 873.

11. Crowfoot Payne, 2000: 108. 

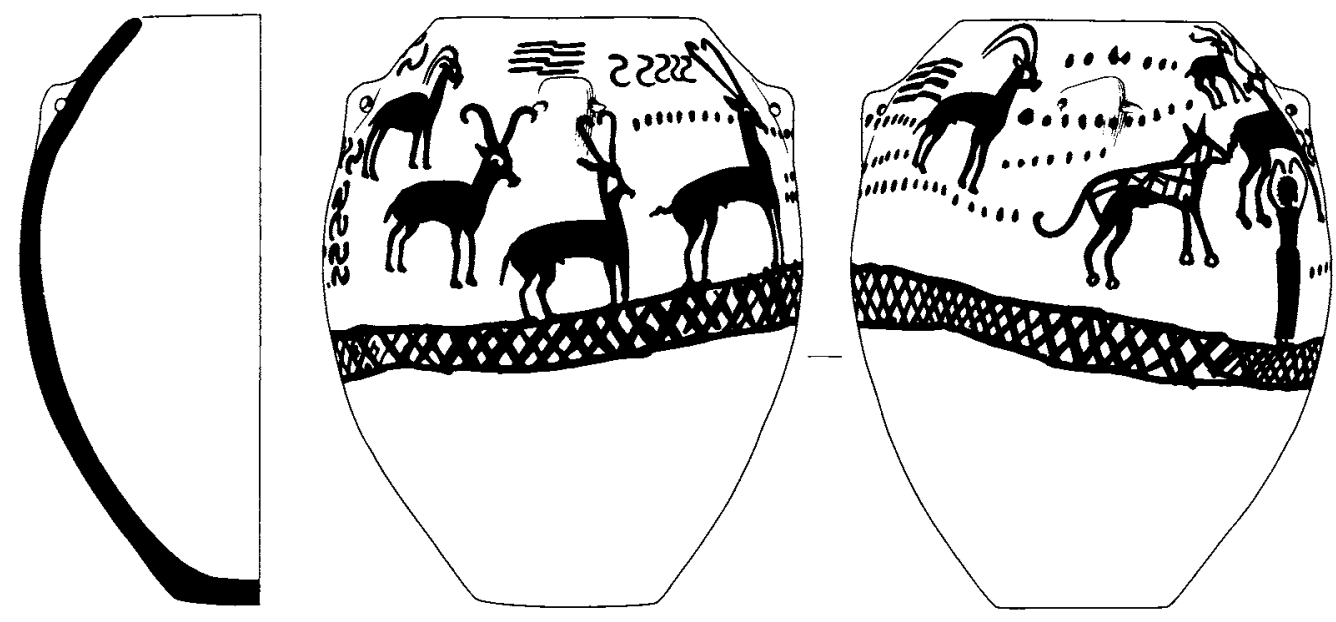

Figura 1. Vaso cerámico del período de Nagada IId2. Crowfoot Payne, 2000: 108, fig. 44, 873. Oxford, Ashmolean Museum, $n^{\circ}$ de inventario: E.2832. Abydos

Presenta a una mujer con los brazos por encima de su cabeza acompañada de un perro y de una serie de cápridos con cornamentas. La representación de este tipo de animales parece estar relacionada con la idea y deseo de renacimiento por lo que estaríamos ante una escena de carácter simbólico y propiciatoria para la caza.

Una pieza que se encuentra en el Ashmolean Museum de Oxford $^{12}$ (fig. 2) presenta una decoración de naves y de otros elementos que acompañan a la única imagen humana presente en el esquema compositivo. Este aislamiento denota su relevancia, pero su importancia también podría deducirse porque se apoya directamente sobre la cabina de uno de los barcos que decora el vaso.

La representación de navíos en la pintura de la cerámica predinástica ha sido una de las características más destacadas de los periodos denominados Nagada II c-d1-d2 (= Petrie S.D. 40-63) por Kaiser ${ }^{13}$.
Para El-Yahky ${ }^{14}$, los barcos dibujados en estos recipientes podrían entenderse en un contexto mágico religioso en el cual estas naves realizarían un viaje a la otra vida. La presencia de embarcaciones con un gran número de remos en períodos faraónicos, que tendrían la misma utilidad a la referida por este autor, corroboraría su planteamiento. Considerando la hipótesis de El-Yahky como correcta, resulta interesante analizar un petroglifo del Uadi Hammamat ${ }^{15}$, en el cual se puede apreciar una figura humana que eleva sus brazos por encima de la cabeza y se apoya sobre un barco. El elemento más llamativo de esta escena es una estrella situada en la parte superior derecha. Algunos autores consideran que durante el Predinástico, el Más Allá se encontraba situado en el cielo estrellado, por lo que este elemento reforzaría la idea de que estas embarcaciones pudieran tener la función de trasportar al difunto a la otra vida.

12. Ashmolean Museum, 1955.566; Tebas. Crowfoot Payne, 2000: 107, figs. 41, 862.

13. Kaiser, 1957: 72.

14. El-Yahky, 1985: 190.

15. Wilkinson, 2003: lám. 9. 


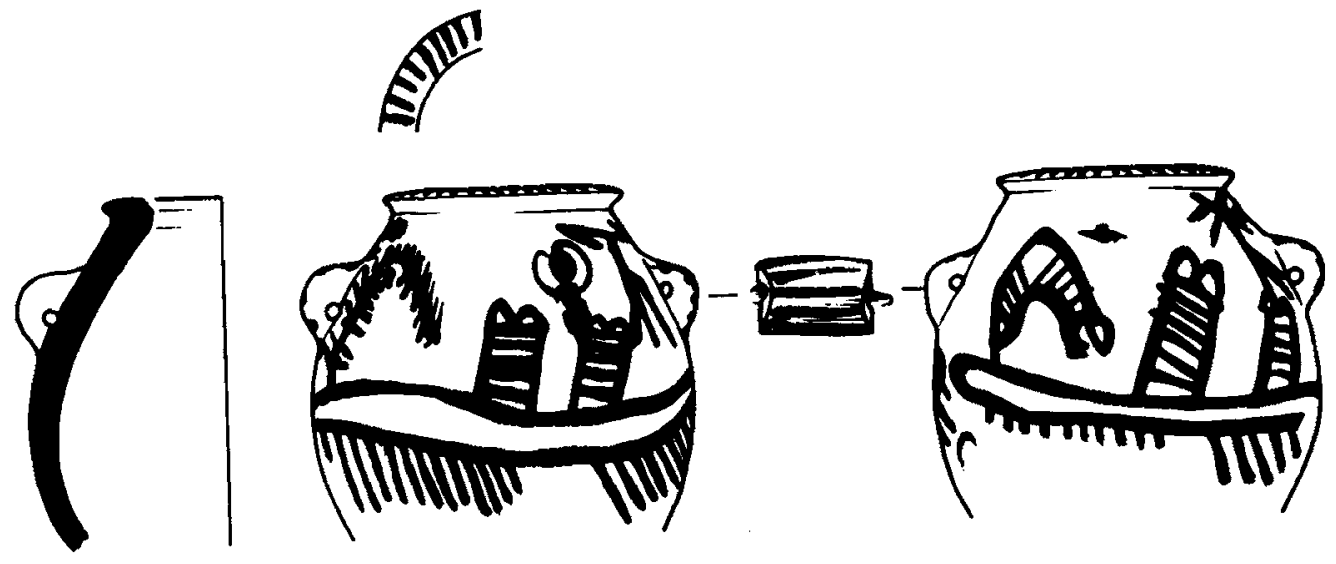

Figura 2. Vaso cerámico con la presencia de una figura femenina sobre la cabina de un barco. Crowfoot Payne, 2000: 107, fig. 41, 862. Oxford, Ashmolean Museum, $n^{\circ}$ de inventario: 1955.566. Tebas

Wilkinson considera que algunas de estas mujeres están relacionadas con el duelo del individuo fallecido ${ }^{16}$. Las imágenes dinásticas que dibujan a las plañideras las muestran tirándose del pelo en señal de dolor, y las figuras femeninas representadas en el vaso del Ashmolean Museum $1895.584^{17}$ (fig. 3a) o acercan completamente sus manos a la cabeza o podrían estar mesándose los cabellos. No será el anterior el único recipiente que muestre a dos mujeres como únicos humanos protagonistas ${ }^{18}$ (fig. 3b). Existe otro vaso en el mismo museo en el que dos figuras femeninas se apoyan sobre las cabinas de una de las embarcaciones representadas en la pieza. Ambas han sido dibujadas con el mismo tamaño denotando con ello la siel vehículo para llegar al Más Allá, tal vez estas mujeres estén presentes en ellos para poder acompañar al difunto en su camino, prefigurando a Isis y Neftis.
Las figuras masculinas acompañan a las femeninas en el esquema compositivo como en una pieza que se halla expuesta en el British $\mathrm{Mu}-$ seum $^{19}$ (fig. 4) y que está decorada con dos barcos que no presentan el mismo estandarte. En una de las caras aparece una mujer con los brazos levantados, cinco dedos en cada mano y no se distinguen sus pies (fig. 4a). Se encuentra acompañada por dos hombres de los cuales uno lleva un tocado de elementos vegetales o plumas que podría indicar que es el líder de la comunidad o una especie de oficiante de algún tipo de ritual. La otra cara (fig. 4b) muestra, de nuevo, una figura femenina acompañada por dos hombres; el que se halla a su derecha apoya su mano sobre el hombro de la mujer, gesto éste similar al de la pieza de Nagada I que se comentó con anterioridad.

El British Museum ${ }^{20}$ conserva otra pieza (fig. 5) que presenta figuras masculinas acompañando a una femenina y tres barcos con distinto

16. Wilkinson, 2003: 155.

17. Ashmolean Museum, 1895.584; Nagada, tumba 454. Crowfoot Payne, 2000: 107-108, fig. 42, 865.

18. Ashmolean Museum, E.2823; Abadiya B. Crowfoot Payne, 2000: 108, fig. 43, 867.

19. Londres, British Museum, EA 35502; El-Amra.

20. British Museum, EA 49570; Semaina. 
estandarte cada uno. La mujer tiene representados los dedos de las manos (tres en cada una) y los pies y su tamaño es mayor que el de los dos hombres; uno de éstos la está tocando el brazo.

En los dos ejemplos anteriores, el individuo masculino que toca a la figura femenina se encuentra a la derecha de ésta, aunque en un ejem- plo estudiado en el Museo Egipcio de El Cairo ${ }^{21}$ son dos los hombres que la acompañan y posan sobre ella la mano.

Para Baumgartel ${ }^{22}$, la postura de los brazos por encima de la cabeza que adoptan las figuras femeninas del periodo de Nagada II estaría representando lo que se ha denominado como
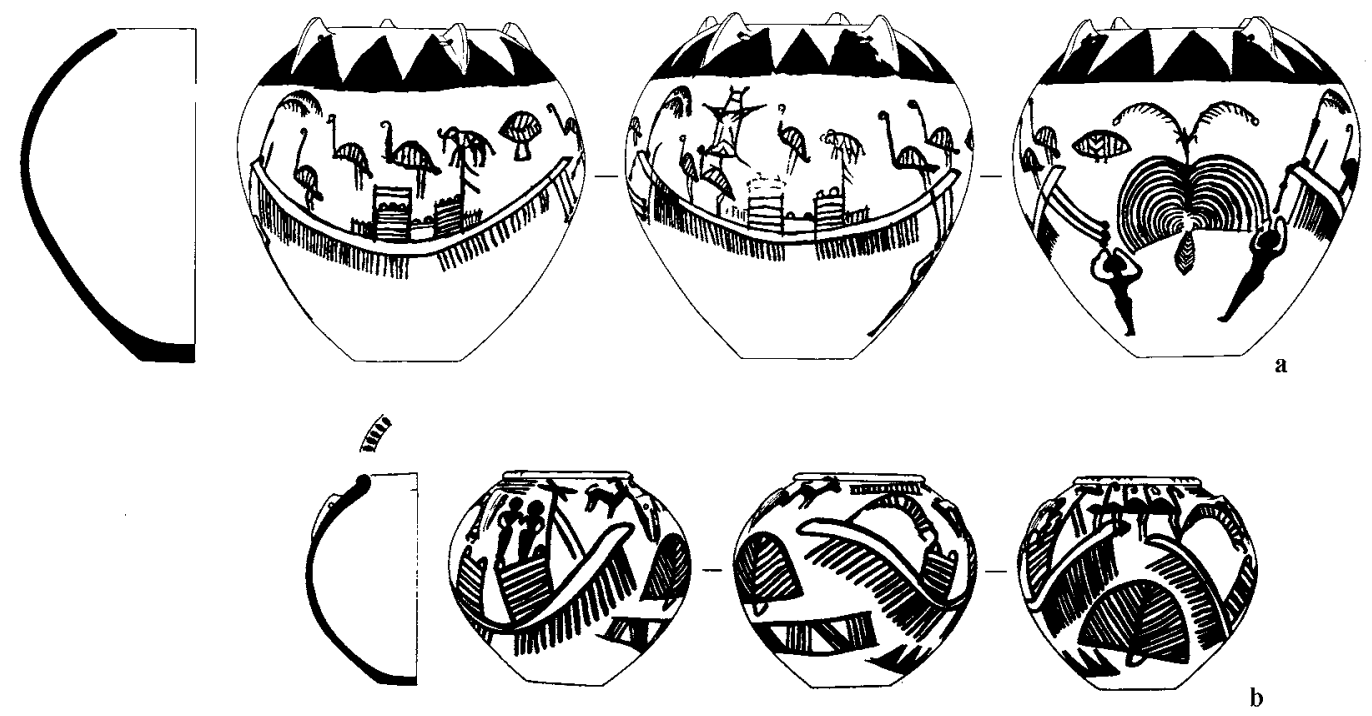

Figura 3. Dos vasos cerámicos con la presencia de dos figuras femeninas. Crowfoot Payne, 2000: 107-108, fig. 42, 865 (a) y 108, fig. 43, 867 (b). Oxford, Ashmolean Museum. a) $n^{\circ}$ de inventario: 1895.584; Nagada, 454. b) $n^{\circ}$ de inventario: E.2823; Abadiya B

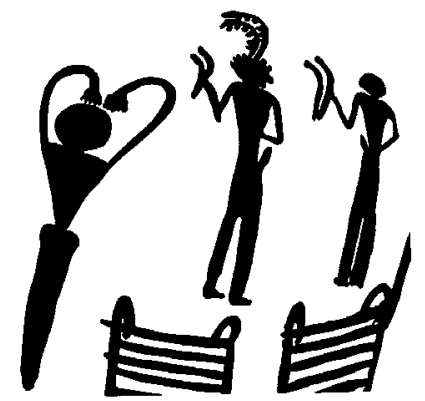

$\mathbf{a}$

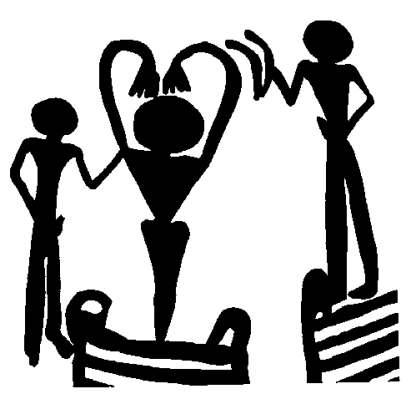

b

Figura 4. Dos detalles de un mismo vaso cerámico. Londres, British Museum. $N^{o}$ de inventario: EA 35502. El-Amra

21. JE $88124=$ SR $2 / 5360 / 0$.

22. Baumgartel, 1947: 64-65. 


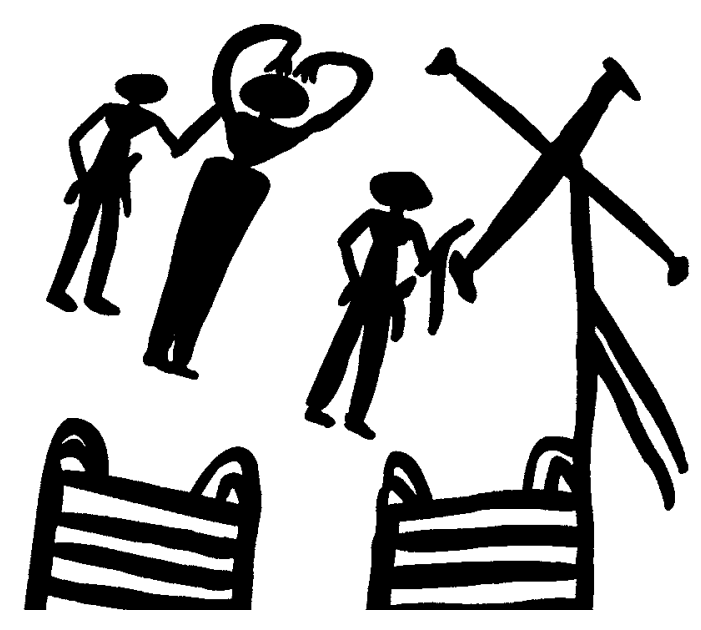

Figura 5. Londres, British Museum, $n^{\circ}$ de inventario: EA 49570. Semaina

“el baile de la vaca". Comparó estas imágenes con las danzas que las mujeres de Sudán realizan levantando sus brazos. La postura que adoptan imitaría las astas del ganado vacuno. Esta autora utiliza este paralelo moderno para indicar que dicho gesto tal vez estuviera evocando la capacidad reproductora de estos animales.

Hassan $^{23}$ ha estudiado las ofrendas predinásticas en las tumbas, el arte rupestre, los diseños en los vasos cerámicos decorados de Nagada II y las diosas egipcias tempranas, para interpretar aspectos de la mujer en el contexto mortuorio-religioso egipcio del Periodo predinástico y dinástico temprano. Este autor considera que las creencias [282 ] y los rituales funerarios en el Egipto calcolítico muestran a la mujer como un agente de nacimiento y renovación, como una diosa madre. Los enterramientos representan para él el útero materno al que vuelven los individuos que, colocados en posición fetal, esperan su renacimiento. Hassan defiende la idea de que las mujeres que aparecen en la cerámica, en terracotas, etc., estarían en la base de la sacralización del rey $^{24}$, por la preeminencia de la diosa vaca en la Paleta de Narmer, por las imágenes de figuras femeninas en la iconografía de Nagada II, por la igualdad en la condición de que gozan las mujeres en la sociedad del Predinástico tardío y por su asociación con el nacimiento, la fertilidad, creación y muerte en dicha sociedad.

El gesto de elevar los brazos por encima de la cabeza también aparece en una serie de figuritas exentas realizadas en arcilla. Hornblower afirma que, tanto en Egipto como en Mesopotamia, estas imágenes femeninas aparecen en las tumbas como un amuleto funerario ${ }^{25}$.

Las interpretaciones de $\mathrm{Ucko}^{26}$ acerca del posible significado de las figurillas antropomorfas son variadas. Según él, podrían estar relacionadas con una ceremonia de iniciación, ya que algunas de éstas acompañan a individuos de corta edad que tal vez no hayan podido participar en algún tipo de ritual, por lo que los padres se encargan de colocarlas junto a ellos. Podrían ser también soportes de apelación a los ancestros o a divinidades para que aumente el rebaño; o figurillas con una utilidad mágica, o muñecas, lo que explicaría la presencia de algunas de ellas en zonas de hábitat. La hipótesis que aporta dicho autor de que sean sirvientes está relacionada con el hecho de que estén frecuentemente asociadas a modelos de animales en las tumbas, donde se podría interpretar que se encuentran para encargarse del cuidado de estos últimos y de otras posesiones en la otra vida.

Siguiendo con los vasos cerámicos, entre los que hemos estudiado hay dos especialmente

23. Hassan, 2004: 779-780.

24. Hassan, 1992: 312.

25. Hornblower, 1929: 32.

26. Ucko, 1968: 427-434. 
llamativos que se encuentran almacenados en los fondos del British Museum ${ }^{27}$ de los que se desconoce su lugar de procedencia y que presentan mujeres que elevan sólo uno de sus brazos.

\section{Mujeres que apoyan las manos en una de LAS CADERAS}

Otra de las posturas que adoptan las figuras femeninas puede apreciarse en un vaso cerámico conservado en el Museo Nubio de Asuán. En este ejemplar, la mujer parece apoyar sus dos manos en la cadera derecha. En otra pieza a la que se hará alusión posteriormente y que se conserva en el Metropolitan Museum de Nueva York también se puede apreciar un ejemplo de dicho gesto.

Existe un petroglifo en Uadi Barramiya ${ }^{28}$, una de las principales rutas que atraviesan el desierto oriental de oeste a este, que representa a dos figuras humanas con esta misma posición. Estos dos personajes poseen un estuche fálico y un tocado de plumas, por lo que los hemos identificado como hombres.

Creemos que, como el resto de las posturas, ésta también tendrá algún sentido ritual, pero no hemos encontrado todavía una explicación que permita entender este gesto.

\section{Mujeres cogidas de las manos}

Un petroglifo en Uadi el-Atwani, al norte del Uadi Hammamat ${ }^{29}$, sugiere que el motivo de un grupo de mujeres con faldas y cogidas de la mano tiene un significado especial en el Egipto prehistórico. También lo indica un vaso cerámico que apareció en la tumba U-502 de Abydos junto al esqueleto de un niño y que se encuentra decorado con ocho figuras femeninas modeladas en arcilla y pegadas por el lado interior de la vasija. Cada una de ellas posee rasgos individuales, pero todas llevan faldas pintadas de blanco y están cogidas de la mano formando un anillo en torno a la parte superior del cuenco. Debido a la semejanza entre ambas representaciones, se ha fechado el petroglifo en el período de Nagada $\mathrm{I}^{30}$.

Este esquema compositivo también se aprecia en las decoraciones de vasos cerámicos del período de Nagada II, como el conservado en el Ashmolean Museum ${ }^{31}$ con número de inventario 1958.345 o el comprado por MacGregor ${ }^{32}$ así como en el mango de oro de un cuchillo que se encuentra actualmente en el Museo Egipcio de El Cairo ${ }^{33}$.

En las tres escenas, la mujer que aparece a la izquierda lleva lo que ha sido denominado por algunos autores como un aloe y por otros como un abanico y las situadas a la derecha no llevan nada, exceptuando la que aparece representada en la pieza del Ashmolean que sujeta un objeto que no ha podido ser identificado.

Tanto en la decoración del mango como en la cerámica comprada por MacGregor aparece un barco representado en la otra cara. En la pieza del Ashmolean no está presente este elemento.

29. Wilkinson, 2003: 78.

30. Wilkinson, 2003: 77-78.

31. Ashmolean Museum, 1958.345.

32. Hendrickx, 2002: 39, fig. 34.

33. JE $34210=$ CG 64868. Saleh y Sourouzian, 1987: 41. 
Los cuchillos como el anteriormente mencionado son interpretados por Adams ${ }^{34}$ como el precedente del instrumento utilizado en el ritual de la Apertura de la Boca. Ann Macy Roth ${ }^{35}$ indica que el denominado $p s \check{s}-k f$ se asemeja a los de cola de pescado y en este caso tendría la misma utilidad que la apuntada por Adams. Roth interpreta este objeto como un utensilio ritual relacionado con el nacimiento y el renacimiento. Piensa que la ceremonia de la Apertura de la Boca podría haber derivado de un culto que aseguraría el nuevo nacimiento y el desarrollo del niño. Según esta autora, estos cuchillos sirven para cortar el cordón umbilical y, por analogía, se utilizarían en este rito con la intención de hacer renacer al difunto para que pueda comer la comida real y la simbólica. Roth explica el refinamiento en la forma de los mismos como una posible manera de mejorar la efectividad en el corte del cordón umbilical. La forma triangular de este tipo de objetos podría corresponderse con la forma del útero materno ${ }^{36}$. La ubicación normal para este tipo de utensilios dentro de las tumbas predinásticas era detrás del cuerpo, sobre todo en los periodos más antiguos, donde se colocaban también otra serie de cuchillos y otras armas potencialmente peligrosas (las figuras femeninas exentas se sitúan también algunas veces en esa zona). En los enterramientos donde el fallecido aparece en posición fetal, estos elementos se colocan detrás de la pelvis ${ }^{37}$.

Si tomamos esta idea como válida, estas mu[284 ] jeres, que parecen bailar, podrían estar actuando en alguna ceremonia cultual de renacimiento al difunto. Formarían parte del sentido ritual del cuchillo al igual que el barco. Este tipo de representación de figuras femeninas agarradas por las manos y el diseño del barco podrían también estar buscando reforzar la intencionalidad del cuchillo.

La última de las piezas que vamos a estudiar se encuentra conservada en el Metropolitan Museum of Art de Nueva York ${ }^{38}$ (fig. 6). En dicha pieza aparecen tres barcos y en uno de ellos podemos apreciar, encima de una de las cabinas y colocados bajo una especie de baldaquino, una figura femenina y una masculina agarradas de la mano (fig. 6a). El tamaño de ella es mayor que el del hombre, lo que puede indicar la relevancia de ésta frente a él. En otra de las embarcaciones volvemos a encontrarnos con dos mujeres apoyadas sobre la cabina izquierda de la misma. Una de ellas parece tener las manos apoyadas en la cadera. Dos personajes masculinos las acompañan en esta escena. Tanto estas dos mujeres como la que aparece con los brazos por encima de la cabeza en el tercer barco, no se sitúan sobre la cabina que porta el estandar-
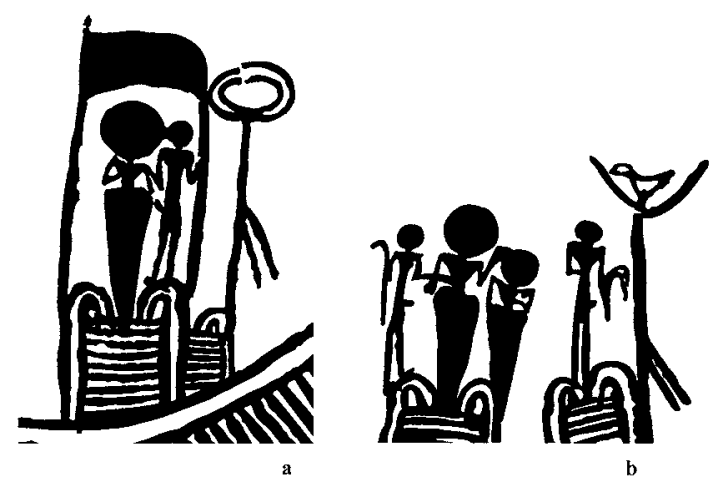

Figura 6. Dos detalles de un mismo vaso cerámico. Nueva York, Metropolitan Museum of Art. $N^{o}$ de Inventario: 20.2 .10

34. Adams, 1988: 37.

35. Roth, 1992: 113-147.

36. Roth, 1992: 129.

37. Roth, 1992: 131.

38. Nueva York, Metropolitan Museum of Art, 20.2.10. 
te. Las tres naves que aparecen en la pieza no llevan el mismo estandarte, por lo que podría tratarse de diferentes embarcaciones que acompañarían al difunto al Más Allá.

\section{Conclusiones}

Las diversas maneras de representar las figuras femeninas indican diferentes participaciones simbólicas de las mismas. Algunas mujeres podrían estar presentes para propiciar la capacidad reproductora de los animales o la caza, mientras que entre las que se encuentran junto a los barcos se distinguiría entre las que formaban parte del cortejo, acompañando al difunto hasta la necrópolis, y las que hacían posible la llegada del difunto al Más Allá, lo que también nos permitiría diferenciar a los barcos en este sentido. La idea de renacimiento del difunto podría, por tanto, estar conectada con estas imágenes femeninas. La lectura iconográfica ofrece muchas posibilidades pero también una gran incertidumbre y sólo estudiando los diferentes vasos en su conjunto podremos formular algunas hipótesis y descartar otras. 


\section{Bibliografía}

AdAMs, B.

1988 Predynastic Egypt. Princes Risborough.

BAUMgartel, E. J.

1947 The Cultures of Prehistoric Egypt. Oxford.

Crowfoot Payne, J.

2000 Catalogue of the Predynastic Egyptian Collection in the Ashmolean Museum. Oxford.

EL-YAHKY, F.

1985 Clarification on the Gerzean boat scenes, BIFAO 85: 187-197.

GRAFF, G.

2004a Les représentations de personnages humains sur les vases peints de Nagada I. TdE 3: 73-82.

2004b Las representaciones de los signos ondulatorios en los vasos nagadienses. $B A E D E$ 14:7-41.

2004c Les peintures sur vases Nagada I-Nagada II. Nouvelle approche sémiologique, en: Hendrickx, S., Friedman, R. F., Cialowicz, K. M. y Chlodnicki, M. (eds.): Egypt at its origins. Studies in Memory of Barbara Adams, Leuven: 765-777.

HaSsAn, F. A.

1992 Primeval Goddess to Divine King. The Mythogenesis of Power in the Early Egyptian State, en: Friedman, R. y Adams, B. (eds.) The Followers of Horus. Studies dedicated to Michael Allen Hoffman. 1944 -1990. Oxford: 307-321.

2004 Between Man and Goddess: The Fear of Nothingness and Dismemberment, en: Hendrickx, S., Friedman, R. F., Cialowicz, K. M. y Chlodnicki, M. (eds.) Egypt at its Origins. Studies in Memory of Barbara Adams, Leuven, 779-799.
HENDRICKX, S.

2002 Checklist of predynastic "Decorated" pottery with human figures, $C C d E 3 / 4$ : $29-45$.

HornBlower, G. D.

1929 Predynastic figures of women and their successors, JEA 15: 29-47.

KAISER, W.

1957 Zur inneren chronologie der Naqadakultur, Archaeologia Geographica 6: 69-77.

Rотн, A. M.

1992 The $p s \check{s}-k f$ and the "opening of the mouth" ceremony: a ritual of birth and rebirth, JEA 78: 113-147.

Saleh, M.; Sourouzian, H.

1987 Official Catalogue the Egyptian Museum. Cairo. Mainz.

UсKо, P. J.

1968 Anthropomorphic Figurines of Predynastic Egyptand Neolithic Crete with comparative material from the Prehistoric Near East and Mainland Greece. London.

Wengrow, D.; BAInes, J.

2004 Images, human bodies and the ritual construction of memory in late predynastic Egypt, en: Hendrickx, S., Friedman, R. F., Cialowicz, K. M. y Chlodnicki, M. (eds.) Egypt at its Origins. Studies in Memory of Barbara Adams, Leuven, 1081-1113.

WILKINSON, T.

2003 Genesis of the Pharaohs. Dramatic new discoveries that rewrite the origins of ancient Egypt. London. 


\section{Trabajos de Egiptología Papers on Ancient Egypt}

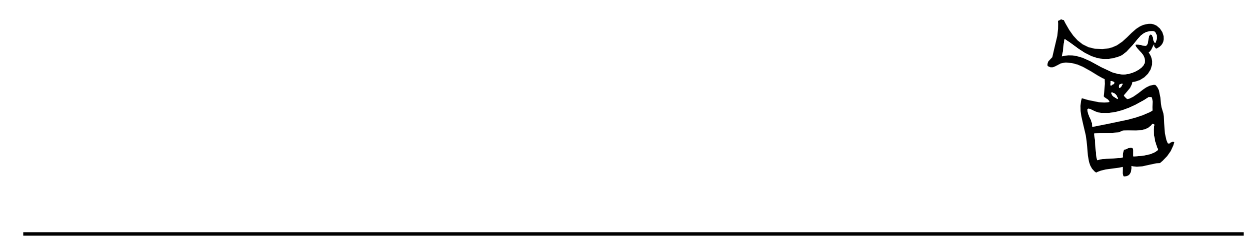

Número 5/1 2009 


\section{Actas \\ III Congreso Ibérico de Egiptología III Congresso Ibérico de Egiptologia}

Editores

Miguel Ángel Molinero Polo Covadonga Sevilla Cueva 


\title{
Editor
}

Miguel Ángel Molinero Polo

Universidad de La Laguna

\section{Consejo Editorial}

\author{
Antonio Pérez Largacha \\ Universidad de Castilla-La Mancha \\ José-R. Pérez-Accino \\ Birkbeck, Universidad de Londres \\ Covadonga Sevilla Cueva \\ Universidad Autónoma de Madrid
}

\section{Comité Científico}

Josep Cervelló i Autuori

Universitat Autònoma de Barcelona

$\mathrm{M}^{\mathrm{a}}$ José lópez Grande

Universidad Autónoma de Madrid

Josep Padró i Parcerisa

Universitat de Barcelona

$\mathrm{M}^{\mathrm{a}}$ Carmen Pérez Die

Museo Arqueológico Nacional, Madrid

Ester Pons Mellado

Museo Arqueológico Nacional, Madrid

José M. Serrano Delgado

Universidad de Sevilla

\section{Colaboradores Editoriales}

Linda Steynor

English editorial assistant

Hervé Mouriacoux

Assistant éditorial pour la langue française 
Trabajos de Egiptología está producida por Isfet. Egiptología e Historia c/ Blanco $1,2^{\circ}$

38400 Puerto de la Cruz

Tenerife-Islas Canarias

España

Maquetación: Proyecto Limón

(C) Autores de los artículos aparecidos

y Consejo Editorial de Trabajos de Egiptología - Papers on ancient Egypt

Depósito Legal: TF-2302-2009

ISSN: $1695-4750$

Imprime: Gráfica Los Majuelos, S.L.L.

imprenta@graficaslosmajuelos.com

Tfno.: 922311455 


\section{Comité Científico \\ III Congreso Ibérico de Egiptología III Congresso Ibérico de Egiptologia}

Miguel Á. Molinero Polo

Universidad de La Laguna

Presidente del Comité Organizador del III Congreso Ibérico de Egiptología

Miembro del Comité Organizador del I Encuentro de Egiptología

Josep Cervelló Autuori

Universitat Autònoma de Barcelona

Presidente del Comité Organizador del II Congreso Ibérico de Egiptologia

José Manuel Galán Allué

Consejo Superior de Investigaciones Cientificas

Director del Proyecto Djehuty, Luxor, Egipto

$\mathrm{M}^{\mathrm{a}}$ Helena Trindade Lopes

Universidad de Lisboa

Directora de la Misión Arqueológica Portuguesa en Menfis

Josep Padró i Parcerisa

Universitat de Barcelona

Director de la Misión Arqueológica de Oxirrinco

Antonio Pérez Largacha

Universidad de Castilla - La Mancha

Miembro del Comité Organizador del I Encuentro de Egiptología

José Ramón Pérez-Accino

Birkbeck College, University of London

Miembro del Comité Organizador del I Encuentro de Egiptología

$\mathrm{M}^{\mathrm{a}}$. Carmen Pérez Díe

Museo Arqueológico Nacional

Directora de la Misión Arqueológica Española en Heracleópolis Magna, Egipto

Covadonga Sevilla Cueva

Universidad Autónoma de Madrid

Miembro del Comité Organizador del I Encuentro de Egiptología 